\title{
HUBUNGAN PENGETAHUAN DAN KETERSEDIAAN AIR DENGAN PEMANFAATAN JAMBAN KELUARGA DI WILAYAH KERJA PUSKESMAS SIKABU KECAMATAN LUBUK ALUNG KABUPATEN PADANG PARIAMAN TAHUN 2016
}

\author{
Nurul Prihastita Rizyana ${ }^{1}$, Dhea Revita Sari Mayanda ${ }^{2}$, Yulia $^{3}$ \\ STIKes Alifah Padang, Indonesia \\ Email : prihastitan@gmail.com
}

\begin{abstract}
ABSTRAK
Data Dinas Kesehatan Kabupaten Padang Pariaman tahun 2015, didapatkan pencapaian program penyehatan lingkungan khususnya pemanfaatan jamban keluarga masih 64,79\%. Sedangkan kasus diare termasuk salah satu distribusi penyakit terbanyak dimana terdapat 8.042 kasus diare. Penelitian ini bertujuan mengetahui hubungan pengetahuan dan ketersediaan air dengan pemanfaatan jamban keluarga di Wilayah Kerja Puskesmas Sikabu Kecamatan Lubuk Alung Kabupaten Padang Pariaman tahun 2016. Jenis penelitian ini adalah deskriptif analitik dengan pendekatan kuantitatif yang telah dilakukan pada bulan Februari - Agustus 2016. Populasi dalam penelitian ini $540 \mathrm{KK}$ yang memiliki jamban. Sampel pada penelitian ini adalah 84 KK diambil secara cluster sampling. Pengumpulan data melalui wawancara menggunakan kuesioner. Didapatkan 56,0\% responden kurang baik dalam pemanfaatan jamban, 51,2\% responden memiliki ketersediaan air yang kurang, 56,0\% responden kurang baik dalam pemanfaatan jamban. Terdapat hubungan pengetahuan dan ketersediaan air dengan pemanfaatan jamban keluarga di Wilayah Kerja Puskesmas Sikabu Kecamatan Lubuk Alung Kabupaten Padang Pariaman Tahun 2016. Kepada Puskesmas Sikabu Kecamatan Lubuk Alung diharapkan meningkatkan penyuluhan, baik secara berkelompok maupun kunjungan rumah dan kepada pemegang kebijakan di Nagari Sikabu agar mengajak tokoh masyarakat dengan cara advokasi untuk menggerakkan masyarakat agar mau memanfaatkan jamban keluarga misalnya lewat forum pengajian, PKK dengan metode ceramah dan diskusi yang dilakukan secara menyeluruh dan terpadu.
\end{abstract}

Kata Kunci

: Pengetahuan, Ketersediaan air, Jamban keluarga

ABSTRACT

Padang Pariaman District Health Department in 2015, reported the achievement of environmental sanitation program in particular the use of toilet families still 64.79\%. Diarrhea was one of highest diseases, from 255428 people there were 8042 cases of diarrhea. This study aims to determine the association of knowledge and availability of water to the utilization of family latrines in Puskesmas Sikabu District of Lubuk Alung Padang Pariaman in 2016. Descriptive analytic Reasearch quantitative approach that has been carried out in FebruaryAugust 2016. The population in this study were 540 households have latrines and 84 families were taken by cluster random sampling. Data collected through interviews and analyzed by univariate and bivariate using chisquare

test. $56.0 \%$ of respondents are less in to use the toilet, $51.2 \%$ of respondents have lack of water availability, $56.0 \%$ of respondents are less to use of toilet. There is a association between knowledge and the availability of water to the utilization of family latrines in Puskesmas Sikabu District of Lubuk Alung Padang Pariaman 2016. Suggestion are to improve the counseling, groups and home visits. For the policy makers have to invite the community leaders to mobilize the community to take advantage of family latrines for example through recitation forum, PKK and discussion conducted a comprehensive and integrated.

Keywords: Knowledge, availability of water, latrines family 


\section{PENDAHULUAN}

Program Penyediaan Air Minum dan Sanitasi Berbasis Masyarakat (PAMSIMAS) merupakan salah satu program pemerintah dalam rangka perwujudan dari tujuan pilar ke-tujuh dari Millenium Development Goals (MDG's) yakni memastikan kelestarian lingkungan, serta target MDG's kesepuluh (mengurangi hingga setengahnya porsi masyarakat yang tidak memiliki akses terhadap air minum aman dan sanitasi dasar) di tahun 2015 (UNDP, 2004).

Hingga tahun 2012 cakupan air bersih di Indonesia mencapai 57\% dan sanitasi baru mencapai 58\%. Cakupan tersebut ditargetkan pada tahun 2015 meningkat menjadi masing-masing 68\% (Dirjen Cipta Karya, 2013). Selain itu, data menunjukkan bahwa cakupan implementasi MDG's Indonesia masih dibawah Malaysia, Kamboja dan Filipina.

Indikator untuk melihat perilaku hidup bersih dan sehat masyarakat sebagaimana dijelaskan Antiningsih(2013) meliputi: meningkatnya perilaku CTPS, meningkatnya perilaku BAB di tempat tertutup, penggunaan air bersih, meningkatnya kepemilikan jamban.

Berdasarkan data yang diperoleh dari Dinas Kesehatan Propinsi Sumatera Barat bahwa tahun 2010 menunjukkan hanya 42,65\% rumah tangga di Sumatera Barat yang memiliki tempat pembuangan tinja sendiri, sebanyak $14,67 \%$ untuk bersama dan sebanyak 9,93\% yang umum. Padahal cakupan jamban harus mencapai $100 \%$ atau semua masyarakat harus memiliki jamban keluarga yang memenuhi syarat kesehatan dirumah (Dinkes Sumbar, 2011).

Sementara di Kabupaten Padang Pariaman diare termasuk salah satu distribusi penyakit terbanyak, dari 255.428 orang terdapat 8.042 kasus diare. Angka kejadian diare di Kabupaten Padang Pariaman pada tahun 2015 yaitu 33,1\% mengalami peningkatan dari tahun sebelumnya yaitu tahun 2014 sebanyak 31,1\%(Dinkes Padang Pariaman, 2015).

Masalah penyehatan lingkungan pemukiman khususnya pada jamban keluarga merupakan masalah kesehatan yang perlu mendapatkan prioritas. Fasilitas jamban keluarga di masyarakat terutama dalam pelaksanaannya tidaklah mudah, karena menyangkut peran serta masyarakat yang biasanya sangat erat kaitannya dengan tingkat ekonomi (Notoatmodjo, 2011). Data Dinas Kesehatan Kabupaten Padang Pariaman tahun 2015, didapatkan pencapaian program penyehatan lingkungan khususnya pemanfaatan jamban keluarga adalah 64,79\% tersebar di 25 Wilayah Puskesmas dari 366.740 jiwa (Dinkes Kabupaten Padang Pariaman, 2015).

Dari seluruh Puskesmas yang ada di Kabupaten Padang Pariaman, hampir semua wilayah kerja yang sudah ikut dalam program PAMSIMAS dan yang paling rendah jumlah Kepala Keluarga yang memiliki jamban keluarga berada di wilayah kerja Puskesmas Sikabu sebanyak 540 KK (26,83\%) yang terdiri dari 11 Jorong (Koto Buruak, Salibutan Kampung Tangah, Padang Mantuang, Pasa Karambia, Sungai Puar, Caung Tarok, Kampani, Sikariah Silangkung, Kampung Pili dan Jajaran). Dari 11 Jorong yang ada di Wilayah Kerja Puskesmas Sikabu didapatkan Kepala Keluarga yang paling sedikit memiliki jamban keluarga berada di Jorong Jajaran yaitu sebanyak $40 \mathrm{KK}$. Berdasarkan teori L Green (1989) dalam Notoatmodjo (2011) bahwa perilaku kesehatan dipengaruhi oleh beberapa faktor seperti faktor predisposisi (pengetahuan, sikap, kepercayaan, keyakinan, nilai-nilai, status ekonomi), faktor pendukung (lingkungan ketersediaan fasilitas dan sumber daya yang ada) dan faktor pendorong (toko masyarakat dan petugas kesehatan) Berdasarkan uraian diatas maka peneliti tertarik melakukan penelitian tentang hubungan pengetahuan dan ketersediaan air dengan pemanfaatan jamban keluarga di Wilayah Kerja Puskesmas Sikabu Kecamatan Lubuk Alung Kabupaten Padang Pariaman Tahun 2016.

\section{II .METODE PENELITIAN}

Penelitian ini merupakan penelitian kuantitatif yang bersifat observasional dengan rancangan penelitian cross sectional / potong lintang, dimana variabel independen (pengetahuan, ketersediaan air) dan variabel dependen (pemanfaatan jamban keluarga) diukur pada saat yang bersamaan, serta melihat hubungan antara variabel independen dan variabel dependen.

84 sampel penelitian diambil dengan menggunakan cluster sampling dari seluruh KK yang memiliki jamban yang ada di Wilayah Kerja Puskesmas Sikabu Kecamatan Lubuk Alung Kabupaten Padang Pariaman berjumlah 540 KK. Analisis data dilakukan menggunakan analisis univariat dan analisis bivariat (uji Chi-square).

\section{HASIL}

\section{Tabel 1 Distribusi Proporsi Responden Menurut Pemanfaatan Jamban, Pengetahuan, Ketersediaan air}

\begin{tabular}{llcc}
\hline \multicolumn{1}{c}{ Variabel } & \multicolumn{1}{c}{ Kategori } & $\begin{array}{c}\text { Freku } \\
\text { ensi }\end{array}$ & Persentase \\
\hline Pemanfaatan jamban & Kurang Baik & 47 & 56,0 \\
& Baik & 37 & 44,0 \\
Pengetahuan & Rendah & 45 & 53,6 \\
\multirow{3}{*}{ Ketersediaan air } & Tinggi & 39 & 46,4 \\
& Tidak Tersedia & 43 & 51,2 \\
& Tersedia & 41 & 48,8 \\
\hline
\end{tabular}


Tabel 2 Hubungan Ketersediaan Air dengan Pemanfaatan Jamban Keluarga di Wilayah Kerja Puskesmas Sikabu Kecamatan Lubuk Alung Kabupaten Padang Pariaman Tahun 2016

\begin{tabular}{lccccc}
\hline \multirow{2}{*}{ Variabel } & \multicolumn{4}{c}{ Pemanfaatan Jamban } & \multirow{2}{*}{ P value } \\
& Kurang baik & \multicolumn{2}{c}{ Baik } & \\
\cline { 2 - 5 } & $\mathrm{f}$ & $\%$ & $\mathrm{f}$ & $\%$ & \\
\hline $\begin{array}{l}\text { Pengetahuan } \\
\text { Rendah }\end{array}$ & 37 & 82,2 & 8 & 17,8 & 0,000 \\
$\quad 10$ & 25,6 & 29 & 74,4 & \\
Tinggi & & & & & \\
Ketersediaan Air & 41 & 5,3 & 2 & 4,7 & 0,316 \\
$\quad \begin{array}{l}\text { Tidak Tersedia } \\
\text { Tersedia }\end{array}$ & 6 & 14,6 & 35 & 85,4 & \\
\hline
\end{tabular}

\section{PEMBAHASAN}

Berdasarkan tabel 1 diketahui bahwa hasil penelitian didapatkan bahwa lebih dari separuh $(53,6 \%)$ responden memiliki pengetahuan rendah tentang jamban. Hal ini buktikan dengan rendahnya pemanfatan jamban sebagai media buang air besar sebanyak $56 \%$. Hal ini sejalan dengan pendapat Alamsyah, (2013) rendahnya pengetahuan masyarakat akan penyakit-penyakit yang dapat ditularkan melalui air sangat berpengaruh terhadap kebiasaan buang air besar mereka. Kurangnya informasi penggunaan jamban di masyarakat membuat kebiasaan buang air besar di sembarang tempat sulit diubah. semakin baik tingkat pengetahuan seseorang dalam maka semakin baik pula tingkat pemanfaatan jambannya. Hal ini dibuktikan dengan hasil penelitian bahwa 53,6\% responden kurang mengetahui akibat dari buang air besar sembarangan.

Upaya yang dapat dilakukan adalah, meningkatkan pengetahuan masyarakat melalui sosialisasi kesehatan, promosi dan kampanye melalui media untuk menanamkan pengetahuan kepada masyarakat. Hal ini dapat pula dilakukan oleh petugas kesehatan di Puskesmas ketika menangani seorang pasien, atau pertemuan lintas sektoral dan masyakarat. Advokasi kepada pejabat kelurahan/kecamatan tentang larangan $\mathrm{BAB}$ di sungai.

Berdasarkan hasil penelitian didapatkan bahwa 84 responden terdapat 43 responden $(51,2 \%)$ tidak tersedia. dimana ditinjau dari sudut ilmu kesehatan masyarakat, penyediaan sumber air bersih harus dapat memenuhi kebutuhan masyarakat karena persediaan air bersih yang terbatas mudah menimbulkan penyakit di masyarakat. Volume rata-rata kebutuhan air setiap individu per hari berkisar antara 150-200 liter atau 35-40 galon. Kebutuhan air tersebut bervariasi dan bergantung pada keadaan iklim, standart kehidupan, dan kebiasaan masyarakat.
Berdasarkan hasil penelitian didapatkan bahwa lebih dari separuh $(56,0 \%)$ responden kurang baik dalam pemanfaatan jamban. Hasil kuesioner pada penelitian ini didapatkan bahwa $55 \%$ tidak menggunakan jamban di rumah dan 52\% keluarga tidak mengajar anak menggunakan jamban yang benar dan 54\% masyarakat berharap bantuan pemerintah untuk memperbaiki kondisi jamban saat ini.

Salah satu sebab kurangnya pemanfaatan jamban adalah kondisi jamban yang kurang memadai, air yang tidak tersedia atau tidak cukup. Menurut analisa peneliti dari hasil penelitian ini mengisyaratkan bahwa sebagian besar responden memanfaatkan lingkungan alam terbuka seperti pantai, kebun dan sungai sebagai tempat buang air besar. Hal ini sesuai dengan hasil penelitian awal yang menyebutkan bahwa sebagian besar masyarakat di Wilayah Kerja Puskesmas Sikabu Kecamatan Lubuk Alung Kabupaten Padang Pariaman tidak menggunakan jamban sebagai tempat buang air besar karena tidak tersedianya air.

Tabel 2 menunjukkan bahwa proporsi pemanfaatan jamban kurang baik lebih banyak pada responden tidak tersedia air $(95,3 \%)$ dibandingkan pada responden dengan air yang tersedia $(14,6 \%)$. Hasil penelitian ini sejalan dengan apa yang dikemukakan oleh Sri Kristiani (2015) menemukan bahwa adanya hubungan antara pengetahuan dengan pemanfaatan jamban keluarga. Demikian pula pada dengan penelitian Arito (2011) semakin tinggi pengetahuan seseorang mengenai jamban maka semakin baik pula pemanfaatan jamban.

Pengetahuan atau kognitif merupakan domain yang sangat penting untuk terbentuknya tindakan seseorang (over behaviour). Apabila sesuatu tindakan didasari oleh pengetahuan, maka tindakan tersebut akan bersifat langgeng dan sebaliknya.

Dalam teori perilaku, pengetahuan merupakan salah satu tahap dari tiga tahapan yang dapat terjadi pada seseorang untuk menerima atau mengadopsi suatu perilaku baru (Notoatmodjo, 2010). Sehubungan dengan pemanfaatan jamban, maka masyarakat yang berpengetahuan baik tentang jamban dengan hubungannya dengan penyebaran penyakit, dapat diharapkan akan memanfaatkan jamban (Alamsyah, 2013).

Berdasarkan hasil penelitian diatas menunjukkan bahwa adanya hubungan pengetahuan dengan pemanfaatan jamban keluarga, hal ini tergambar dari persentase hasil penelitian ini dimana responden dengan pengetahuan yang tinggi lebih cenderung memanfaatkan jamban dengan baik, sedangkan responden dengan pengetahuan yang rendah cenderung kurang baik dalam pemanfaatan jamban.

Selain itu penyebab adalah pengetahuan masih kurang, disebabkan informasi kurang seperti 
kurangnya penyuluhan dari tenaga kesehatan, masyarakat belum seluruhnya terpapar media seperti spanduk, poster yang menyangkut pemanfaatan jamban. Responden masih sebatasi mengetahui informasi belum mampu mengaplikasikan tindakan untuk memanfaatkan jamban.

Selain itu penyebab adalah pengetahuan masih kurang, disebabkan informasi kurang seperti kurangnya penyuluhan dari tenaga kesehatan, masyarakat belum seluruhnya terpapar media seperti spanduk, poster yang menyangkut pemanfaatan jamban. Responden masih sebatasi mengetahui informasi belum mampu mengaplikasikan tindakan untuk memanfaatkan jamban.

Berdasarkan hasil penelitian didapatkan proporsi pemanfaatan jamban yang kurang baik lebih banyak pada responden yang memiliki ketersediaan air yang kurang $(95,3 \%)$ dibandingkan pada responden yang memiliki ketersediaan air yang cukup $(14,6 \%)$. Tingginya persentase bahwa kondisi jamban di suatu daerah sangat rendah karena persyaratan yang ditetapkan oleh Kementerian Kesehatan yang menyatakan bahwa jika salah satu persyaratan tidak ada maka jamban tersebut dikategoikan tidak memenuhi syarat kesehatan. Dan yang paling banyak ditemukan pada umumnya adalah ketersediaan air yang sangat sedikit sehingga berdampak pada kondisi jamban dalam keadaan kotor atau tidak dalam keadaan bersih. Disamping itu pula penyebab tidak tersedianya air di fasilitas pembuangan tinja karena masyarakat pada umumnya berada pada tingkat ekonomi rendah sehingga sulit untuk membangun fasilitas jamban termasuk didalamnya penyediaan air untuk membersihkan jamban tersebut (Elisabeth (2007).

\section{KESIMPULAN}

1. Lebih dari separuh $(56,0 \%) \mathrm{KK}$ kurang baik dalam pemanfaatan jamban di Wilayah Kerja Puskesmas Sikabu Kecamatan Lubuk Alung Kabupaten Padang Pariaman Tahun 2016.

2. Lebih dari separuh $(51,2 \%) \mathrm{KK}$ tidak tersedia air yang kurang di Wilayah Kerja Puskesmas Sikabu Kecamatan Lubuk Alung Kabupaten Padang Pariaman Tahun 2016.

3. Lebih dari separuh $(56,0 \%)$ KK kurang baik dalam pemanfaatan jamban di Wilayah Kerja Puskesmas Sikabu Kecamatan Lubuk Alung Kabupaten Padang Pariaman Tahun 2016.

4. Terdapat hubungan pengetahuan dengan pemanfaatan jamban keluarga di Wilayah Kerja Puskesmas Sikabu Kecamatan Lubuk Alung Kabupaten Padang Pariaman Tahun 2016.

5. Terdapat hubungan ketersediaan air dengan pemanfaatan jamban keluarga di Wilayah Kerja Puskesmas Sikabu Kecamatan Lubuk Alung Kabupaten Padang Pariaman Tahun 2016.

\section{SARAN}

Berdasarkan hasil penelitian yang dilakukan, diharapkan

1. Bagi Puskesmas Sikabu Kecamatan Lubuk Alung

Puskesmas Sikabu Kecamatan Lubuk Alung agar meningkatkan dalam penyuluhan, baik secara berkelompok maupun kunjungan rumah.

2. Bagi Tokoh Masyarakat

Diharapkan kepada pemegang kebijakan di Nagari Sikabu agar mengajak tokoh masyarakat dengan cara advokasi untuk menggerakkan masyarakat agar mau memanfaatkan jamban keluarga misalnya lewat forum pengajian, PKK dengan metode ceramah dan diskusi yang dilakukan secara menyeluruh dan terpadu.

3. Bagi Peneliti Selanjutnya

Diharapkan bagi peneliti selanjutnya agar dapat melanjutkan penelitian ini dengan metode yang berbeda dan jumlah sampel yang lebih besar serta variabel lain yang dapat mempengaruhi pemanfaatan jamban keluarga.

\section{DAFTAR PUSTAKA}

[1] Alamsyah, 2013. Pilar Dasar Ilmu Kesehatan Masyarakat. Yogyakarta ; Nuhamedika.

[2] Dinkes Kabupaten Padang Pariaman, 2015. Profil Kesehatan

Kabupaten Padang Pariaman.

[3] Kartono, 2006. Pemimpin dan Kepemimpinan. PT. Rajagrafindo Persada

[4] Maryuni, 2013. Perilaku Hidup Bersih dan Sehat (PHBS). Jakarta : TIM

[5] Meiridhawati, 2012. Faktor yang berhubungan dengan pemanfaatan Community Led Total Sanitation (CLTS) di Kenagarian Kurnia Selatan Kecamatan Sungai Rumbai Kabupaten Dharmasraya. Skripsi FKM Unand. Padang.

[6] Notoatmodjo, 2010. Metodologi Penelitian Kesehatan. Jakarta : Rineka Cipta.

[7]__ 2011. Kesehatan Masyarakat Ilmu dan Seni Edisi Revisi. Jakarta ; Rineka Cipta. 
[8] Nursalam, 2013. Konsep Penerapan Metode Penelitian Ilmu Keperawatan. Jakarta: Salemba Medika

[9] PP No. 16 tahun 2005 tentang Pengembangan Sistem Penyediaan Air Minum.

[10] PP N0. 72 dan 73 tahun 2005 tentang Pemerintahan Desa dan Pemerintahan Kelurahan.

[11] PP No. 7 tahun 2004 tentang RPJMN Renstra 2004-2009 yaitu Pembangunan Prasarana dan Sarana Air Minum dan Sanitasi yang berkelanjutan
[12]Rubbins P. Stephen, 2007. Prinsip-prinsip Perilaku Organisasi. Edisi Kelima,. Erlangga, Jakarta

[13]Susenas, 2002. Survey Sosial Ekonomi Nasional. Jakarta.

[14] Sumardi dan Dieter, 2005. Kemiskinan dan Kebutuhan Pokok, Jakarta : CV.Rajawali

[15] UU No 7 tahun 2004 tentang Sumber Daya Air.

[16] UU No. 32 tahun 2004 tentang Pemerintahan Daerah. 